\title{
Asymmetric organocatalytic reductions mediated by dihydropyridines $\uparrow$
}

\author{
Stephen J. Connon*
}

\author{
Received 27th July 2007 \\ First published as an Advance Article on the web 11th September 2007 \\ DOI: $10.1039 / b 711499 k$
}

Catalytic asymmetric reduction reactions have long been the preserve of the transition metal catalyst. Inspired by the myriad efficient enzyme-catalysed reduction reactions routine in biological systems, chemists have recently begun to design chiral metal-free organocatalysts that employ synthetic dihydropyridine NADH analogues as the hydride source with impressive results. Recent developments in this burgeoning field are discussed.

\section{Introduction}

Given the prevalence of chiral methine groups in both biologicallyand pharmaceutically relevant molecules it is perhaps unsurprising that the search for increasingly more efficient and general catalytic methodologies for the asymmetric addition of a molecule of hydrogen (formally or otherwise) to prochiral $\mathrm{sp}^{2}$-hybridised substrates has remained at the forefront of catalytic asymmetric synthesis for the last four decades ${ }^{1}$ and was recognised by the awarding of a share in the Nobel prize in 2001. ${ }^{2,3}$ Until recently, benchmark homogeneous catalyst systems for enantioselective hydrogenation/hydrogen transfer were based on the use of a central metal ion, ${ }^{1}$ e.g. $\mathrm{Rh}, \mathrm{Ru}, \mathrm{Co}$, Ti or $\mathrm{Zr}$ (for example, Irbased catalysts are recently emerging as highly useful catalysts for the asymmetric reduction of unfunctionalised olefins ${ }^{4}$ ) bound to

Centre for Synthesis and Chemical Biology, School of Chemistry, University of Dublin, Trinity College, Dublin 2, Ireland.E-mail: connons@tcd.ie; Fax: +3531671 2826; Tel: +35318961306

$\dagger$ The author would like to thank Science Foundation Ireland and the Irish Research Council for Science Engineering and Technology for financial support.

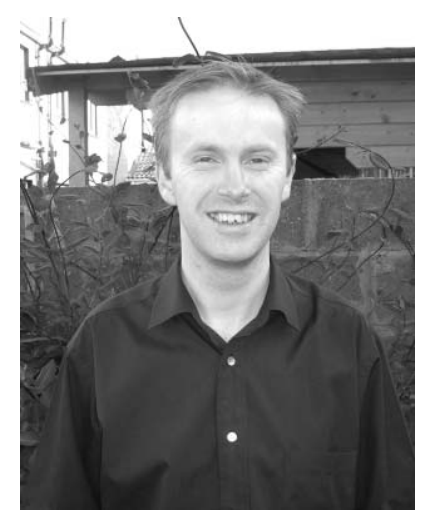

Stephen Connon was born in Dublin in 1976 and graduated from Dublin City University in 1997. He then moved to University College Dublin to study for a Ph.D. on the chemistry of pyridine reactive intermediates under the supervision of Prof. A. F. Hegarty, which was completed in 2000. After being awarded an Alexander von Humboldt fellowship he spent two years at the Technische Universität Berlin as a postdoctoral Stephen J. Connon fellow in Prof. Dr S. Blechert's laboratories, studying the design of new homo- and heterogeneous olefin metathesis catalysis. In 2003 he was appointed to the staff of Trinity College as a Lecturer in the School of Chemistry. His research interests include organocatalysis, the discovery and development of novel synthetic methodology and the design of new anti-cancer and anti-bacterial agents. a chiral (most often phosphine in the case of $\mathrm{Rh}, \mathrm{Ru}$ or Ir-based catalysts) ligand.

While transition metal catalysts for asymmetric reduction reactions have proven spectacularly successful on the whole, in recent times chemists have been inspired by the outstanding efficacy of biological enzymatic systems to develop metal-free organocatalysts $^{5,6}$ for (inter alia) enantioselective reduction reactions that rely on neither strong enthalpic substrate-metal (ion) binding interactions nor the formation of a metal-hydride species. Such de novo designed organocatalysts in principle hold promise as robust, inexpensive, chemoselective and less functional group sensitive alternatives to complement existing metal-based systems. To date, these catalysts (with one exception) employ stoichiometric amounts of readily available 1,4-dihydropyridine derivatives as a mild organic 'hydride' source. A short monologue on this topic appeared in $2005,{ }^{7}$ which summarised the early developments in the field - the aim of this work is to provide an update of selected major developments in this rapidly maturing domain.

Natural enzymatic systems routinely employ nicotinamide adenine dinucleotide (NADH) and flavin adenine dinucleotide $\left(\mathrm{FADH}_{2}\right)$ as cofactors in a diverse array of reduction reactions in vivo. ${ }^{8}$ Westheimer and Mauzerall were the first to demonstrate that synthetic dihydropyridine analogues of NADH could be used to mediate direct hydrogen transfer. ${ }^{9,10}$ It was found that 1-benzyldihydronicotinamide (BDNA, 1) reduced dyestuff $\mathbf{2}$ to its leuco base $\mathbf{3}$ with concomitant formation of pyridinium ion 1a in aqueous solvent (Scheme 1). Deuterium labelling experiments demonstrated that only a 4-deuterio-analogue of the reductant (and not 2- or 6-deuterated variants) transferred deuterium to the product. While $\mathbf{1}$ could not reduce pyruvic acid (5), a low yielding hydrogen transfer from Hantzsch dihydropyridine $\mathbf{4}^{11}$ did occur at higher temperature, albeit in low yield. ${ }^{12}$

Subsequent studies on the reduction of thioketones ${ }^{13}$ indicated that the kinetics of these reduction processes were unaffected by either the presence of molecular oxygen or common radical traps and that the reactions proceeded more rapidly in polar solvents and displayed a significant kinetic isotope effect $\left(k_{\mathrm{H}} / k_{\mathrm{D}}=4-5\right)$ when the dihydropyridine is labelled at C-4 with deuterium. The authors concluded that the mechanism involves the transfer of one 'hydride ion'. These findings later proved somewhat controversial due to discrepancies between the magnitude of the kinetic isotope effect and the product isotope compositions in these types of reactions, which seemingly provided evidence for the existence of 

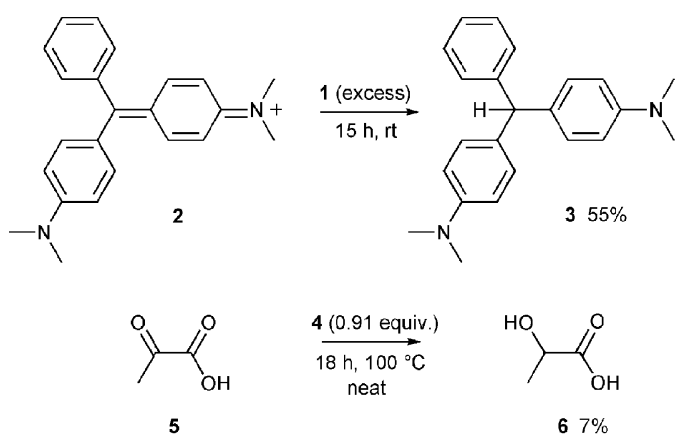

5

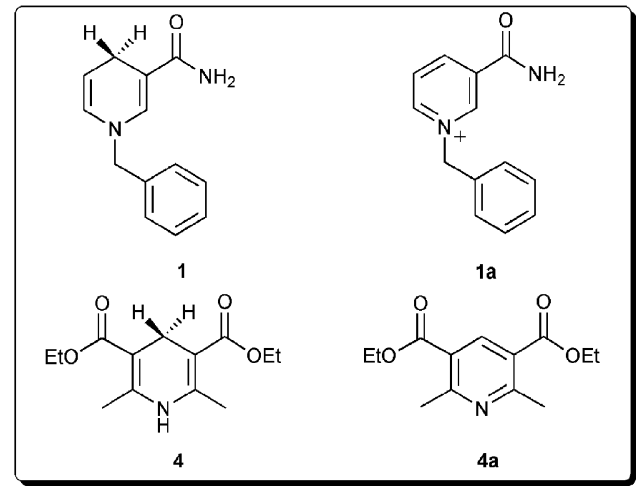

Scheme 1 Westheimer's reduction of $\mathbf{2}$ and $\mathbf{5}$ with $\mathbf{1}$ and $\mathbf{4}$ respectively.

discrete intermediates along the reaction coordinate not expected in a synchronous hydride transfer mechanism. ${ }^{14}$ While it was later demonstrated by Bruice et al. that these anomalies can be explained using quantum mechanical arguments and the detection of both productive and unproductive side reactions, ${ }^{15}$ more recent incontrovertible spectroscopic evidence has confirmed the existence of radical intermediates in some reduction processes mediated by dihydropyridines. ${ }^{16}$ The current mechanistic picture is complex and dependant on reaction conditions - it, however, does seem clear that in certain cases the reaction can be described as an electron-transfer driven process ${ }^{16}$ (A, Fig. 1), which (particularly if the molecule to be reduced is not a strong single electron oxidant ${ }^{17}$ ) is often difficult to distinguish kinetically from synchronous hydride transfer (B, Fig. 1). ${ }^{15,18}$

In the years following Westheimer's work, dihydropyridines ${ }^{19}$ were found to serve as mild, useful reagents capable of reducing organic substrates such as $\alpha, \beta$-unsaturated electrophiles, ${ }^{20}$ imines, ${ }^{21}$ iminium ions, ${ }^{22}$ aldehydes, ${ }^{23}$ ketones ${ }^{24}$ and other functional groups ${ }^{25}$ in the absence of metal ions under either thermal or Brønsted acid-catalysed conditions.

\section{Asymmetric organocatalytic reductions}

The design of chiral dihydropyridines for enantioselective reduction reactions has been an intensively investigated field for over three decades, however, efforts have been strongly focussed on reagents devised for use in conjunction with metal (usually 2+) ions for the reduction of activated carbonyl-based substrates. For example, Kanomata et al. reported that chiral bicyclic dihydropyridine $\mathbf{7}$ reduced $\alpha$-keto ester $\mathbf{8}$ to afford $(R)$-methyl mandelate (9) with almost perfect enantiopurity in the presence of stoichiometric amounts of $\mathrm{Mg}\left(\mathrm{ClO}_{4}\right)_{2}$ (Scheme 2). ${ }^{26,27}$ However, such catalyst systems (in the main) were either inactive or unselective in the

\section{A - stepwise hydride transfer}<smiles>[R]N1C=CC[C@H](C(N)=O)C=C1[C@H](C)O[Na]</smiles><smiles>[R]N1C=C[C@H](C(N)=O)C(C(N)=O)=C1</smiles>

\section{B - synchronous hydride transfer}

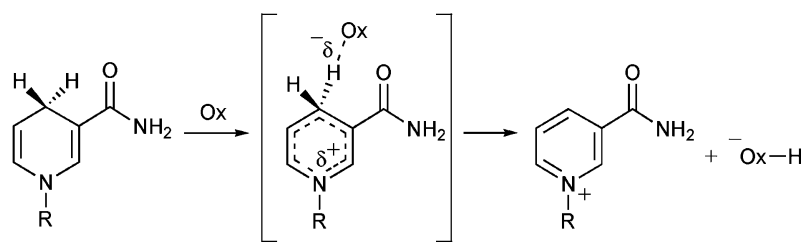

Fig. 1 Mechanism of reduction reactions mediated by NADH analogues.

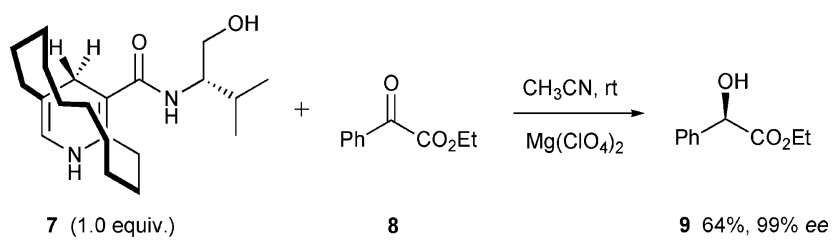

Scheme 2 Kanomata's bicyclic dihydropyridine- $\mathrm{Mg}^{2+}$ system.

absence of the metal additive and as such are not within the scope of this survey. ${ }^{28,29}$

While the potential synthetic utility of dihydropyridine derivatives in reduction processes had been appreciated and explored since the 1950's, little regarding the corresponding metal-free asymmetric processes was known until recent times, which have witnessed an explosion of interest in the design of synthetic organocatalytic systems based on enzymatic design principles. Recent developments are summarised below and are organised according to the class of catalyst involved.

\section{Iminium ion catalysis}

In 2000, MacMillan et al. ${ }^{30}$ demonstrated that $\alpha, \beta$-unsaturated aldehydes could be activated in a face-selective fashion by exposure to the conjugate acids of chiral cyclic secondary amines such as $\mathbf{1 1}$ via the formation of an iminium ion 12. Since the condensation is reversible in the presence of trace amounts of water the amine salt could be used in substoichiometric amounts, which quickly led to a new field commonly called 'iminium ion catalysis' (Fig. 2) ${ }^{6,31}$

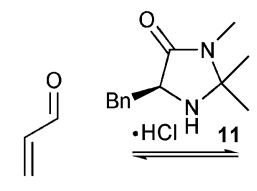

10

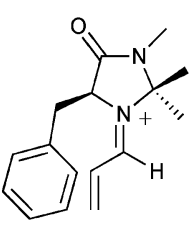

12
- iminium ion more electrophilic than the aldehyde forces the formation of the $(E)$-iminium isomer - benzyl group shields one olefin face

- after reaction at the alkene moiety the iminium ion can be hydrolysed to release the catalyst geminal dimethyl group

Fig. 2 Iminium ion catalysis — basic principle 
List and co-workers were the first to report an efficient, highly enantioselective organocatalytic reduction of $\alpha, \beta$-unsaturated aldehydes. In exploratory studies using an iminium ion catalysis strategy, it was found that unsaturated aldehydes could be reduced by $\mathbf{4}$ in the presence of catalytic amounts of simple ammonium salts such as dibenzyl ammonium trifluoroacetate $e^{32}$ at room temperature. The reaction also proceeded in the presence of cyclic ammonium catalysts, which led to the first asymmetric variant of the reaction promoted by chiral salt $\mathbf{1 3}$ (Scheme 3). ${ }^{33}$ Further optimisation of the catalyst structure and reaction conditions (10 $\mathrm{mol} \%$ ammonium trichloroacetate catalyst 16, 1.02 equiv. of $\mathbf{4}$, dioxane, $13{ }^{\circ} \mathrm{C}, 48 \mathrm{~h}$ ) allowed the isolation of $\mathbf{1 5}$ in $83 \%$ yield and $94 \%$ ee. Interestingly, both 14 and its $(Z)$-isomer 17 (and even 1 : 1 mixtures of $\mathbf{1 4}$ and 17) furnished the same product enantiomer in almost identical yield and enantioselectivity. ${ }^{34}$
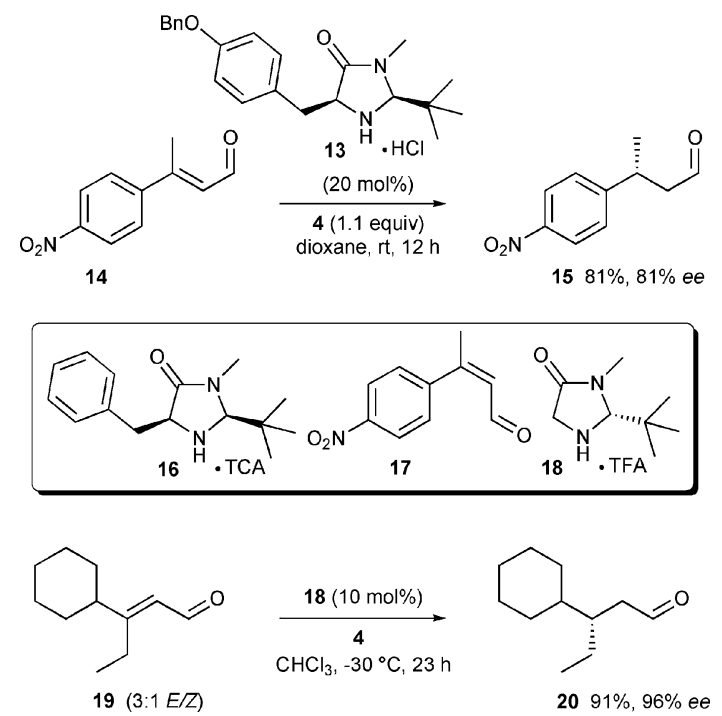

Scheme 3 The first enantioselective organocatalytic reductions.

Very shortly after List's initial report, ${ }^{33}$ MacMillan et al. disclosed the results of a very similar independent study, which found that catalyst 18 could promote highly enantioselective reductions of trisubstituted aldehydes (irrespective of their geometric purity) at $-30{ }^{\circ} \mathrm{C}$ (Scheme 3). ${ }^{35}$

List proposed that the very convenient (in a practical sense) lack of stereospecificity in these reactions, which allows the use of $E-Z$ alkene mixtures, is due to a rapid interconversion of the iminium ion isomers $\mathbf{2 1}$ and $\mathbf{2 2}$ via enamine $\mathbf{2 3}$ on the hydride addition timescale, which leads to the selective formation of $(\boldsymbol{R})-\mathbf{1 5}$ due to a faster addition of hydride to $(\boldsymbol{E})$-22 than to $(\boldsymbol{Z})-\mathbf{2 1}$ (Scheme 4). ${ }^{34}$

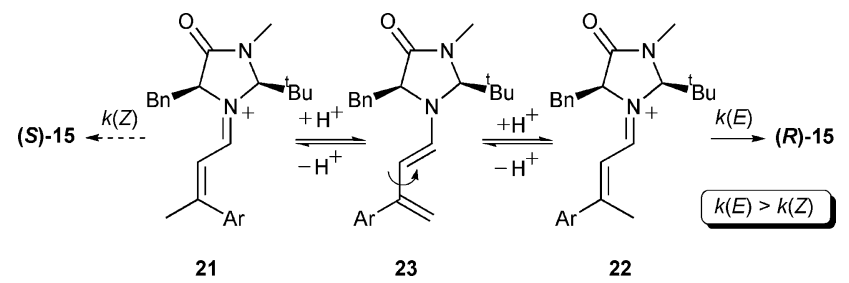

Scheme 4 Proposed mechanism of the non-stereospecific enantioselective reduction of $(E-Z)$-unsaturated aldehydes.
This iminium ion catalysed reduction methodology was later expanded to include more challenging ketone substrates. MacMillan found that catalysts designed for use with enal substrates incorporating a tert-butyl group such as $\mathbf{1 6}$ and $\mathbf{1 8}$ were incompatible with more hindered enone substrates, however, the less bulky ammonium ion $\mathbf{2 4}$ which was known from a previous study ${ }^{36}$ to catalyse enantioselective Diels-Alder reactions involving cyclic enones via iminium ion catalysis - promoted highly enantioselective reduction of cyclic enones such as $\mathbf{2 5}$ with the tert-butyl Hantzsch ester 27 under mild conditions (Scheme 5). ${ }^{37}$

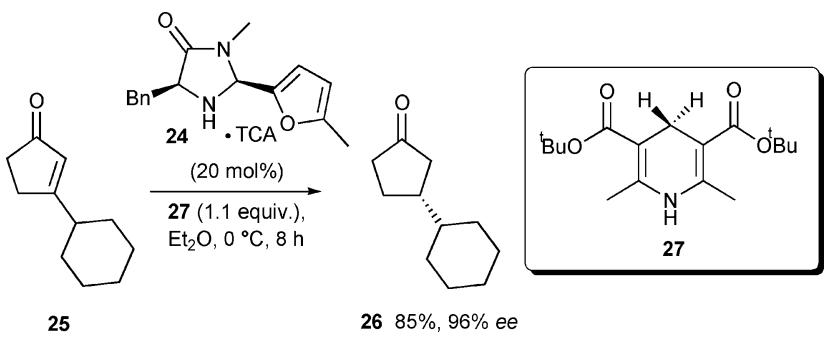

Scheme 5 Enantioselective reduction of cyclic enones using catalyst 24.

List sought a different approach to the problem associated with the incompatibility of $\mathbf{1 6}$ with enone substrates. Noticing that there was a significant contribution from the counteranion towards both catalyst activity and selectivity, the Müllheim group designed a new class of ammonium ion catalyst (of which $\mathbf{2 8}$ is representative) in which the chiral information is incorporated in a BINOLderived counterion component. ${ }^{38}$ Under optimised conditions, morpholium ion $\mathbf{2 8}$ could catalyse the enantioselective reduction of $\mathbf{1 4}$ to furnish $\mathbf{1 5}$ in $98 \%$ ee (the highest yet reported for this class of substrate) and $90 \%$ yield, while the unhindered, industrially relevant $(E)$-citral (29), which proved a poor substrate for use with catalysts such as $\mathbf{1 6}$ and $\mathbf{1 8}$ ( $40 \%$ ee), could be reduced to $(R)$-cintronellal (30) in good yield and excellent enantioselectivity.

Very shortly thereafter, List et al. reasoned that more hindered enone substrates would be more amenable to reaction with less bulky primary amine-derived analogues of 28. Screening studies subsequently identified the $(S)$-valine-derived material $\mathbf{3 2}$ as the optimum salt combination capable of promoting highly selective reduction reactions of a variety of cyclic ketones at elevated temperature (Scheme 6). A single example involving an acyclic enone was also reported ( $84 \%$ ee). The chirality in both ionic components of $\mathbf{3 2}$ are genuinely 'matched'; analogous catalysts derived from either glycine or the opposite antipode of the phosphoric acid promoted reduction with moderate to poor levels of stereoselectivity. ${ }^{39}$ This 'asymmetric counteranion directed catalysis' strategy appears to be a simple yet powerful method for the tuning of an ammonium ion catalyst's properties without necessarily requiring the catalyst's amino unit to be redesigned/resynthesised from scratch and should play an important role in the design of catalysts for these reactions in the future.

\section{Brønsted acid catalysis of enantioselective imine reduction}

Undoubtedly the most convenient organocatalytic alternative to metal-based Lewis acids is the proton, and it has been established for some time that reactions that proceed with a considerable increase in basicity at a heteroatom are susceptible to the influence 
<smiles>CC(C)=CCCC(C)=CC=O</smiles>

29<smiles>CC(C)C1=CC(=O)CCC1</smiles>

33

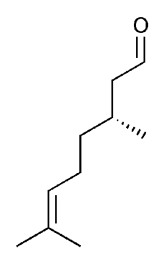

$3071 \%, 90 \%$ ee

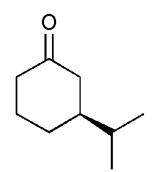

34 94\%, 98\% ee

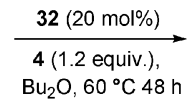

$\mathrm{Bu}_{2} \mathrm{O}, 60^{\circ} \mathrm{C} 48 \mathrm{~h}$

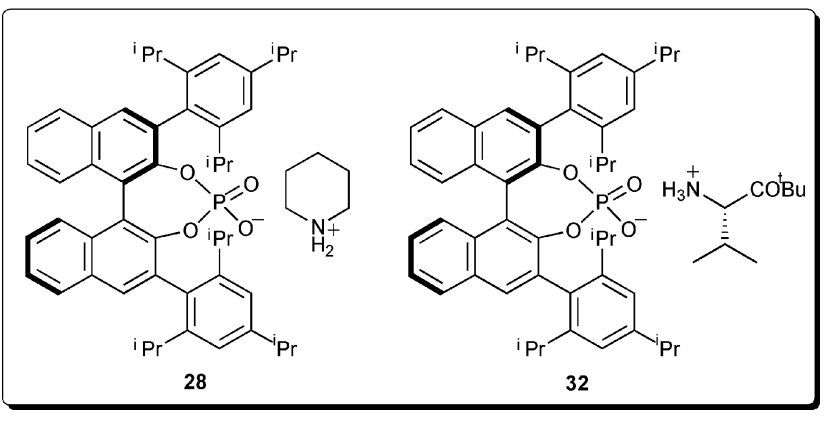

Scheme 6 'Asymmetric counteranion directed catalysis'.

of general acid catalysis. ${ }^{40,41}$ In 1998 , Jacobsen et al. ${ }^{42}$ pioneered the development of highly efficient chiral (thio)urea catalysts for enantioselective Strecker reactions, which spawned a new class of hydrogen-bond donating catalysts for a wide range of asymmetric addition reactions to imines. ${ }^{6, g, h, k}$ However, despite the overall success of this strategy, to the best of our knowledge it has not yet been reported to be applicable to the corresponding organocatalytic asymmetric 'hydride' reduction reactions of imines. ${ }^{43}$ At the time of writing, it appears that these reactions are best promoted in an enantioselective fashion using stronger chiral acids potentially capable of the protonation of the imine prior to the formation of the transition state (specific acid catalysis).

Singh and Batra reported the first example of an asymmetric metal-free reduction reaction of an achiral imine in $1989 .{ }^{44}$ The benzophenone-derived imine 35 could be converted to amine 36 by 4 and a variety of chiral acids in good to excellent yields and poor to moderate levels of enantioselectivity. Of the acids surveyed, the hydrochloride salts of $(S)$-cysteine, $(S)$-serine and $(S)$-histidine proved to be the best additives with $(S)$-cysteine furnishing 36 with the highest levels of enantioselectivity (Scheme 7). It should be noted that while this study was certainly ahead of its time, it is also almost bereft of experimental details and as such cannot be classified as an organocatalytic transformation as the loadings of the acid additives utilised in these reactions are not disclosed. ${ }^{45}$<smiles>C/C(=N\c1ccccc1)c1ccccc1</smiles>

35

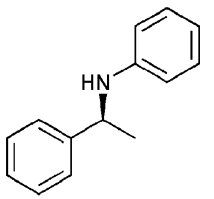

$3655 \%, 62 \%$ ee
Scheme 7 The first asymmetric Brønsted-acid mediated imine reduction.
In 2004, Akiyama et $a l^{46}$ and Terada and Uraguchi ${ }^{47}$ independently developed a new class of axially chiral phosphoric Brønsted acid catalyst (37 and 38 respectively, Fig. 3). ${ }^{48}$ These catalysts are conformationally rigid and (rather unusually) possess a single highly acidic proton for substrate activation. ${ }^{49}$ The extent (in a spacial context) of the influence of the molecule's chiral axis is extended through the incorporation of aryl substituents (the presence of which is crucial for good asymmetric induction) adjacent to the BINOL-derived oxygen atoms. The presence of the Lewis basic phosphoryl moiety in proximity to the acidic proton potentially allows for the simultaneous activation of both electrophilic and nucleophilic reaction components (bifunctional catalysis). Compounds $\mathbf{3 7}$ and $\mathbf{3 8}$ promoted highly enantioselective Mannich-type reactions between $N$-aryl- and $N$-Boc substituted imines with silyl ketene acetals ${ }^{46}$ and acetyl acetone. ${ }^{47,50}$<smiles>O=[N+]([O-])c1ccc(-c2cc3ccccc3c(-c3c4c(cc5ccccc35)OP(=O)(O)O4)c2OP(=O)(O)O)cc1</smiles>

37<smiles>O=P(O)(Oc1ccccc1)Oc1c(-c2ccc(-c3ccc4ccccc4c3)cc2)cc2ccccc2c1-c1c(-c2ccc(-c3ccc4ccccc4c3)cc2)cc2ccccc2c1O</smiles>

Fig. 3 Prototype phosphoric acid catalysts designed independently by Akiyama and Terada.

These seminal studies highlighted the strong potential of phosphoric acids for the activation of imine substrates. Soon afterward, Rueping et al. demonstrated the first enantioselective organocatalytic imine reduction catalysed by variants of 37-38.

Optimum catalyst $\mathbf{4 1}$ at $20 \mathrm{~mol} \%$ level allowed the synthesis of $\mathbf{4 0}$ from 39 with high yield and enantiopurity (Scheme 8)..$^{51,52}$ Both electron donating and withdrawing substituents on the acetophenone-derived aromatic ring were well tolerated, however, no substrates incorporating two aliphatic substituents or nonmethyl ketones were reported in this study. A specific acid catalysis mechanism was proposed involving an initial protonation of the substrate by the catalyst to afford ion pair $\mathbf{4 3}$, which undergoes reduction by 4 to generate the amine product $\mathbf{4 4}$ and protonated $4 \mathrm{a}$ (45), which regenerates the catalyst after a proton transfer process (Scheme 8).

Soon afterward, List independently reported a parallel study that identified the bulky $\mathbf{4 6}$ as the optimum catalyst. ${ }^{53}$ The reduction of acetophenone-derived ketimines promoted by $\mathbf{4 6}$ gave improved results (80-90\% yield and $80-93 \%$ ee) at lower temperatures compared to those obtained by Rueping. ${ }^{51}$ Organocatalyst 46 was also highly active - it could be utilised at $1 \mathrm{~mol} \%$ levels and was shown to be compatible with an imine derived from an aliphatic ketone. This publication also detailed an example representing the first enantioselective organocatalytic reductive amination reaction. Acetophenone (47) was first treated with aniline 48 under conditions conducive to ketimine formation followed by in situ reduction with 4 catalysed by $\mathbf{4 6}$. Finally, oxidative deprotection of the PMP moiety afforded primary amine 49 in very good yield and enantiomeric excess (Scheme 9). 


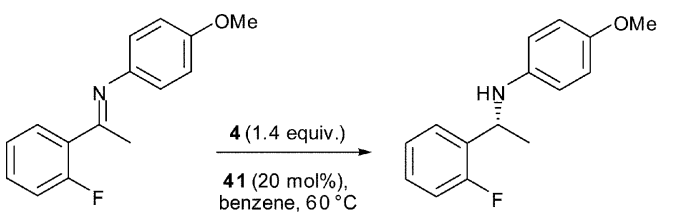

39

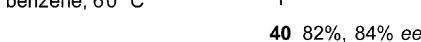

$82 \%, 84 \%$ ee

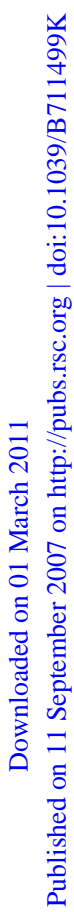

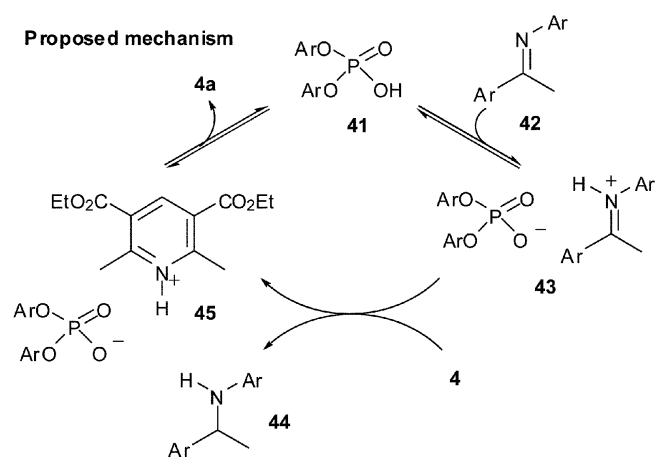
metric reduction of imines.

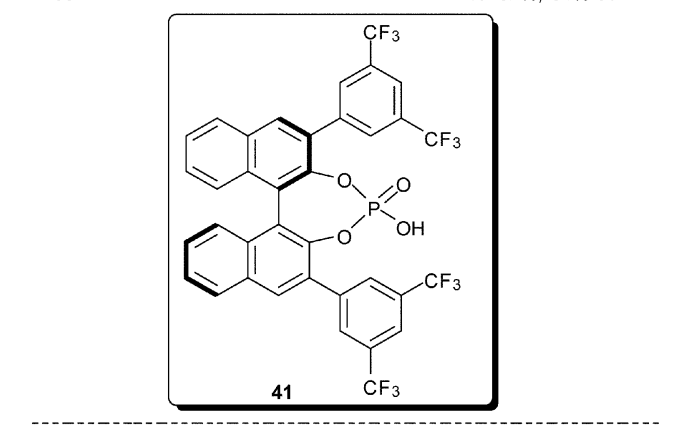

Scheme 8 Enantioselective phosphoric acid derivative-catalysed asym-

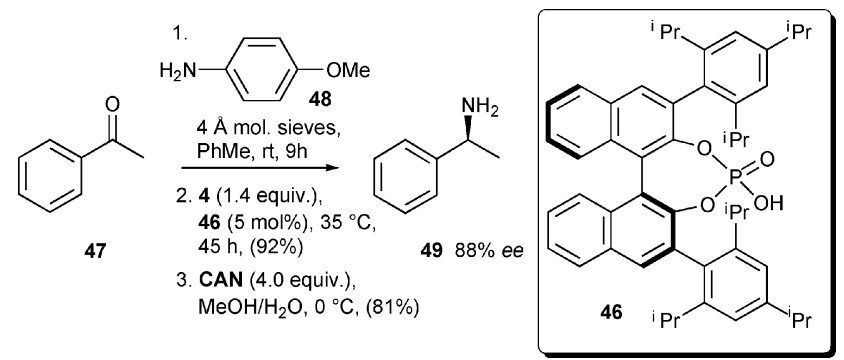

Scheme 9 The first organocatalytic asymmetric reductive amination.

Very shortly after List's study ${ }^{53}$ MacMillan et al. published the efficient and highly enantioselective reductive coupling of $\mathbf{4 8}$ and a variety of substituted and unsubstituted acetophenones catalysed by the triphenylsilyl-substituted catalyst $\mathbf{5 0} .^{54}$ The reaction was found to be applicable to the enantioselective reductive amination of either aromatic or aliphatic ketones. Experimental, computational and X-ray crystallographic studies indicated that the imine substrate for the reduction reaction must be derived from a methyl ketone - substituents larger than methyl led to the shielding of the 'open' si-face of the catalyst-bound (activated) imine in the stereocentre-forming reaction transition state. However, this considerable limitation of the methodology was cleverly exploited in the enantioselective reductive amination of highly challenging substrates such as 2-butanone (51) and the selective (mono) reductive amination of bis-ketone $\mathbf{5 3}$ (Scheme 10).

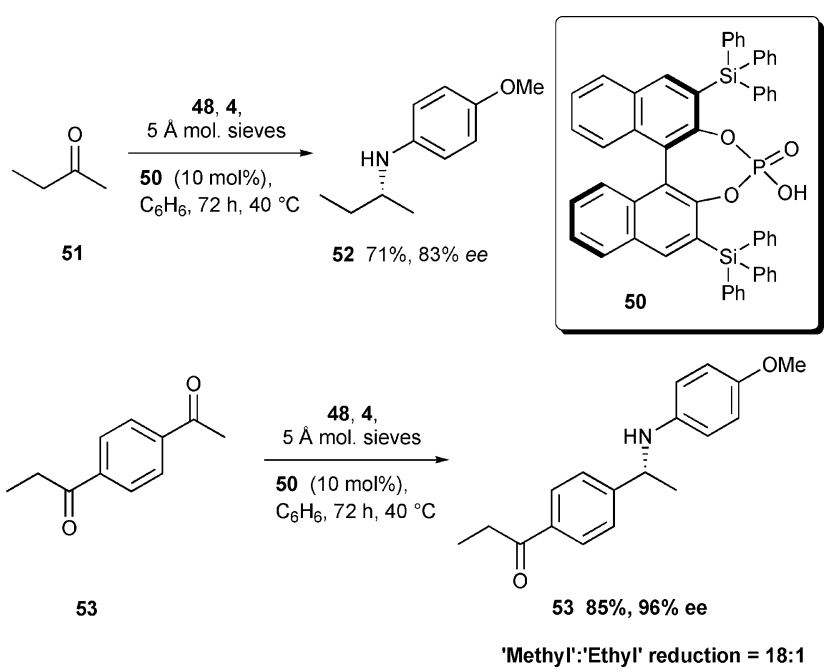

Scheme 10 Methyl $v s$. ethyl selectivity in reductive amination reactions promoted by $\mathbf{5 0}$.

While it is obvious that aldehydes cannot undergo direct enantioselective reduction due to the formation of an achiral product, List's group have discovered an interesting variation on this theme where racemic $\alpha$-branched aldehyde substrates can furnish enantioenriched products on reductive amination via a dynamic kinetic resolution process. ${ }^{55}$ Organocatalytic reductive amination of racemic aldehyde $\mathbf{5 4}$ with modified Hantzsch ester 27 at $6{ }^{\circ} \mathrm{C}$ catalysed by $\mathbf{4 6}$ allowed the isolation of almost enantiopure $\mathbf{5 5}$ in good yield (Scheme 11). The proposed origin of the enantioselectivity is as follows - reaction of $\mathbf{5 4}$ with $\mathbf{4 8}$ generates both enantiomers of imine $\mathbf{5 6}$, which rapidly equilibrate in the presence of acid via achiral enamine 57. The chiral catalyst then effects a highly diastereoselective reduction of (in this case) $(\boldsymbol{R})-\mathbf{5 6}$, which is rapidly replenished by the aforementioned equilibration process to give a product of high enantiopurity (Scheme 11). While this promising methodology is undoubtedly a very useful addition to the field, it is currently limited to the use of aromatic amines, however, aldehydes containing both aromatic and aliphatic substituents can be employed.

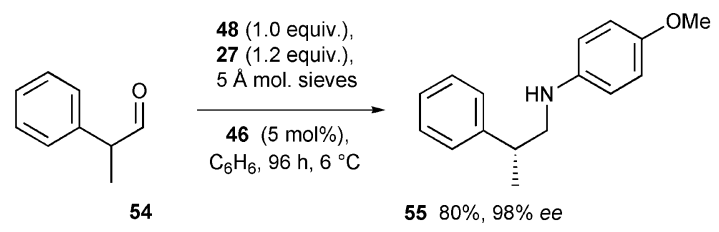

Dynamic kinetic resolution - proposed mechanism

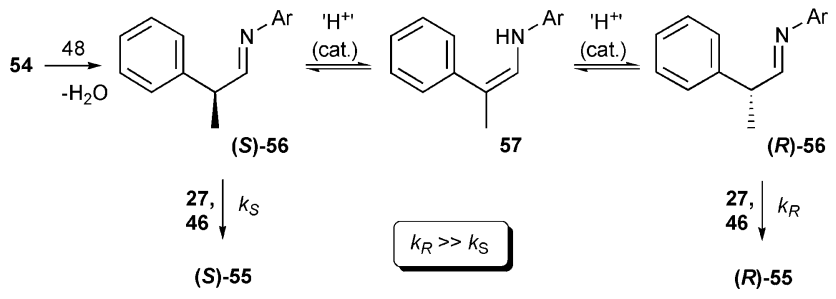

Scheme 11 Catalytic asymmetric reductive amination of aldehydes via dynamic kinetic resolution. 
Antilla and co-workers ${ }^{56}$ have recently utilised an organocatalytic hydride reduction process in the direct enantioselective synthesis of protected $\alpha$-amino acids. Using a VAPOL-derived phosphoric acid (58) developed in their laboratory, readily available $\alpha$-imino esters (such as $\mathbf{5 9}$, Scheme 12) could be efficiently and selectively reduced to the corresponding amines with stoichiometric amounts of $\mathbf{4}$. It is notable that $\mathbf{5 8}$ was found to be superior to both $\mathbf{5 0}$ and a small library of alternative chiral phosphoric acid catalysts in this reaction. ${ }^{57}$ The method was general; imino esters derived from both aromatic and aliphatic $\alpha$-keto esters could be transformed smoothly, although the authors state that an analogous process involving in situ imino ester formation (i.e. a reductive amination methodology) is as yet inefficient and is selective only with aliphatic moiety-substituted starting materials.
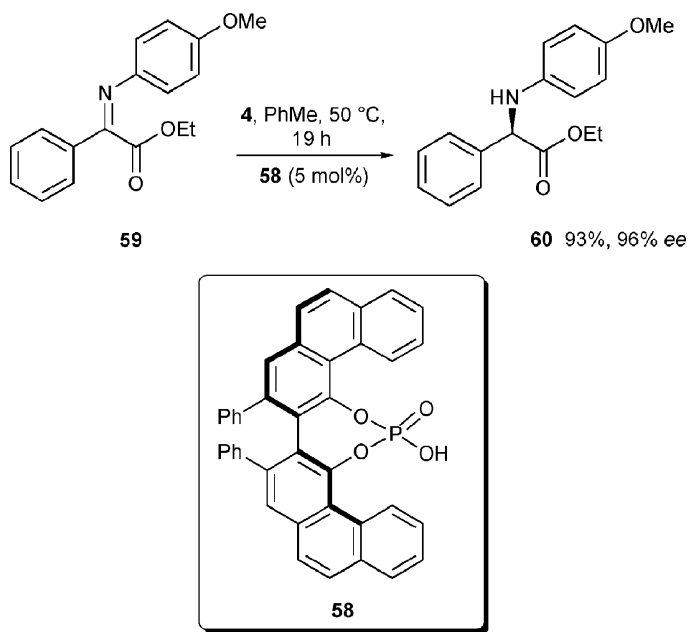

Scheme 12 Direct reductive organocatalytic synthesis of enantioenriched protected amino acids.

Given that prior to the advent of this breakthrough enzymeinspired technology there was a relative dearth of catalytic asymmetric strategies for reductive amination processes, ${ }^{58}$ the discovery and development of these efficient and highly enantioselective reactions represents a most welcome addition to the organic chemist's toolbox. It seems likely, as investigation in this field intensifies, that additional improvements in substrate scope (non-methyl ketone-derived imines, use of non-aniline coupling partners) will add further to the utility of this already most powerful of transformations.

\section{Brønsted acid catalysis of enantioselective heterocycle reduction}

Rueping et al. ${ }^{59}$ exploited the iminium ion-like behaviour of protonated quinolines to bring about the highly enantioselective organocatalytic synthesis of biologically important tetrahydroquinolines. For example, treatment of 2-substituted quinoline 61 with phosphoric acid catalyst $63(2 \mathrm{~mol} \%)$ and excess 4 led to the formation of $\mathbf{6 2}$ in excellent yield and enantioselectivity. The methodology was also applied to the two-step synthesis of natural products (-)-angustureine (64), (+)-cusparine (65) and (+)-galipinine (66) in $>90 \%$ ee. It was proposed that protonation of the quinoline substrate gives ion pair $\mathbf{A}$, which undergoes reduction by $\mathbf{4}$ to give enamine $\mathbf{B}$. Protonation of $\mathbf{B}$ by the catalyst gives a second quinolinium ion pair $\mathbf{C}$, which is the substrate for the subsequent stereocentre-forming reduction event (Scheme 13) ${ }^{60}$
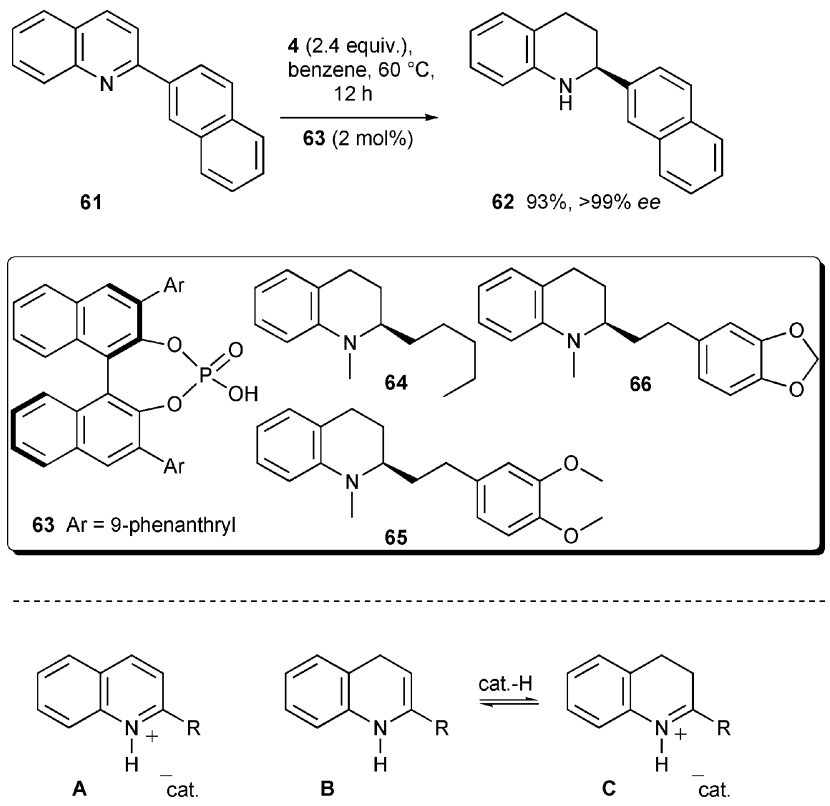

Scheme 13 Enantioselective reduction of quinolines.

Later, the same group extended this methodology to include pyridine derivatives ${ }^{61}$ and benzo-fused thiazines, oxazinones and oxazines - the latter class of substrate could be reduced efficiently using loadings more usually associated with benchmark transition metal catalyst systems (substrate-catalyst ratio $=10000: 1$, Scheme 14). The products of this class of reaction are of considerable medicinal/pharmaceutical interest. ${ }^{62,63}$

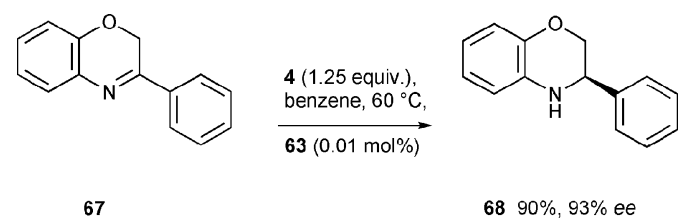

Scheme 14 Efficient enantioselective reduction of a benzoxazine.

\section{Asymmetric organocatalytic domino processes involving reduction}

The high stability and functional group tolerance of organocatalysts (generally speaking) makes their use in cascade reactions a desirable and realistic goal. ${ }^{64}$ Such organocatalytic processes to some extent mimic the complex multistep, multienzyme catalysed biosynthetic pathways ubiquitous in nature and offer potential advantages over more conventional transformation-purificationtransformation etc. strategies in terms of convenience, faster realtime overall conversion of the starting material to the product and (most importantly for cascades involving two or more asymmetric processes) higher enantioselectivity (vide infra).

In 2006, MacMillan and co-workers designed asymmetric organocatalytic cascade sequences involving the use of both 'iminium' and 'enamine' type catalysis with chiral secondary amine promoters. ${ }^{65}$ Treatment of enal 69 with 27 and catalyst 18 (as the TCA salt) followed by subsequent reaction with electrophilic 
fluorine source $\mathbf{7 0}$ promoted by catalyst $\mathbf{1 1}$ (as the DCA salt) furnished $\alpha$-fluoroaldehyde $\mathbf{7 1}$ with outstanding enantioselectivity and very good diastereoselectivity in one pot (Scheme 15). The proposed mechanism is outlined in Scheme 15; the first catalytic cycle consists of an iminium ion mediated asymmetric reduction (as per Fig. 2 and Scheme 3), which generates aldehyde 75. The addition of the second catalyst leads to the formation of enamine 77 (via iminium ion 76), a single face of which can then react with $\mathbf{7 0}$ to form iminium ion $\mathbf{7 8}$ and (after hydrolysis) product $\mathbf{7 1 .}$ This formal addition of HF to an alkene is remarkable in that two seemingly quite structurally similar secondary amines can execute two discrete tasks synergistically in a one-pot process to afford products with two contiguous chiral centres with excellent stereocontrol. The excellent level of catalyst (as opposed to substrate) control in the formation of the second stereogenic centre is obvious from the observation that a repeat of the reaction using the opposite antipode of $\mathbf{1 1}$ in the second cycle (under otherwise identical conditions gives anti-71 (62\% yield, 9 : 1 syn-anti, 99\% ee) with excellent levels of enantioselectivity. ${ }^{66}$
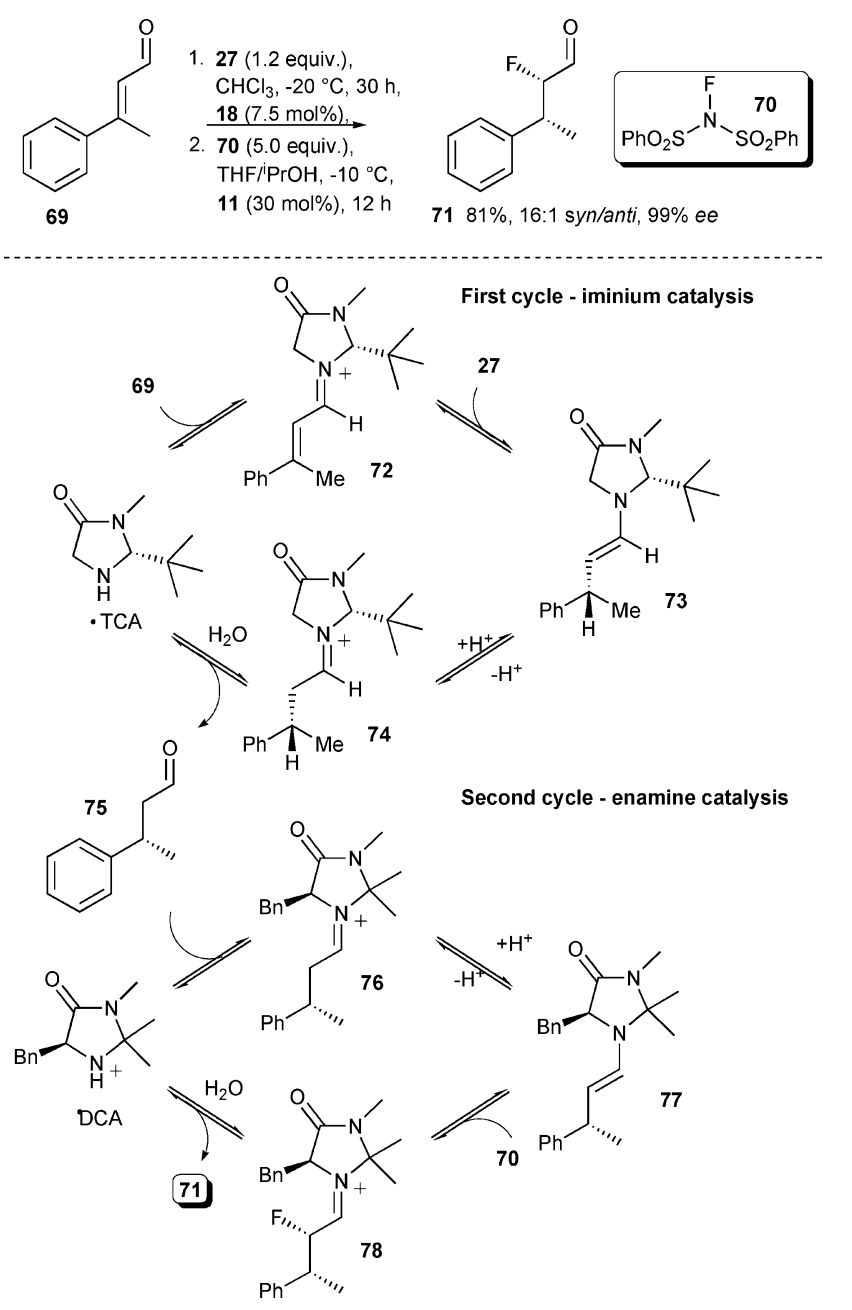

Scheme 15 MacMillan's asymmetric reduction-fluorination cascade process.

At almost the same time, List et al. reported an enantioselective organocatalytic reductive cyclisation reaction. ${ }^{67}$ The strategy is similar to that outlined in the previous example except the electrophilic component that reacts in the second catalytic cycle is a tethered Michael acceptor and a single catalyst system is used. Ammonium catalyst $\mathbf{1 6}$ (as the $\mathrm{HCl}$ salt) could promote first the reduction (iminium ion catalysis using $\mathbf{4}$ as the reductant) and then the Michael cyclisation (enamine catalysis) of substrates such as 79 in one pot. Chemo-, regio-, enantio- and diasterocontrol in these processes were excellent and the methodology is not confined to aromatic substrates; analogues with tethers leading to the formation of 5 and 6 membered ring products were also compatible (Scheme 16).

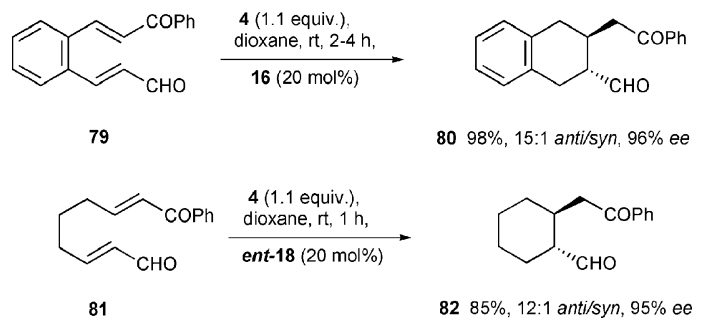

Scheme 16 Organocatalytic asymmetric reductive Michael cyclisation.

Córdova and Zhao reported that a reductive Mannich-type reaction is also feasible. ${ }^{68}$ Using $(S)$-proline derived catalyst $\mathbf{8 3}$ as its benzoic acid salt, enal 69 was asymmetrically reduced by 4 and then reacted with the imino ester electrophile 59 (the limiting reagent) to give the unnatural protected amino acid $\mathbf{8 4}$ with excellent stereocontrol. Just as was the case in MacMillan's earlier study ${ }^{65}$ it was found that catalyst control in the second cycle was excellent - the anti-diastereomer of $\mathbf{8 4}$ could be prepared by simply adding $(R)$-proline $(35 \mathrm{~mol} \%)$ to the reaction after the initial reduction had taken place (Scheme 17).

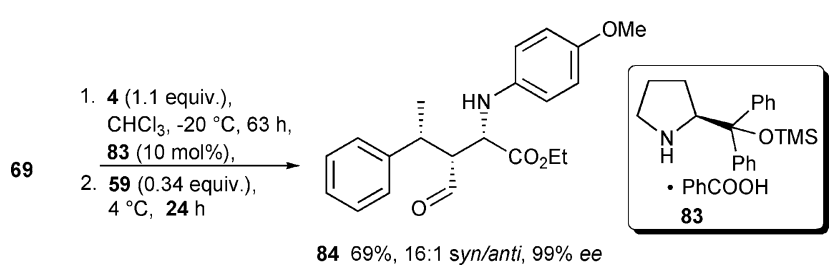

Scheme 17 Organocatalytic reductive Mannich reaction.

List and $\mathrm{Zhou}^{69}$ found that enantioenriched cyclohexylamines could be prepared from 1,5-diketones and anilines using an organocatalytic reductive cascade process. The reaction of diketone 85 with 48 and 4 catalysed by $\boldsymbol{e n t}-\mathbf{4 6}$ yielded cyclohexylamine 86 in good yield and excellent enantioselectivity (Scheme 18). It was posited that the reaction proceeds through the acid-catalysed formation of enamine 87, which cyclises and eliminates water under acidic conditions to give the iminium ion substrate for the two successive asymmetric reduction reactions. The high isolated yields of cyclohexylamine products from these reactions indicate that they are highly chemoselective-little 'double' reductive amination was observed and the chemoselectivity (1,4- vs. 1,2reduction) was excellent.

Recently a complex four-component amino acid-catalysed Knoevenagel-reduction-Robinson annulation sequence has been developed by Ramachary and Kishor. ${ }^{70}$ 1,3-Diketone 90, benzaldehyde (91) and 4 were allowed to react in the presence of (S)-proline in dichloromethane, followed by a change of solvent, 


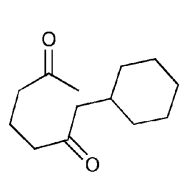

85<smiles>C=C(NC1=CC(=O)CCC1)C1CCCCC1</smiles>

87
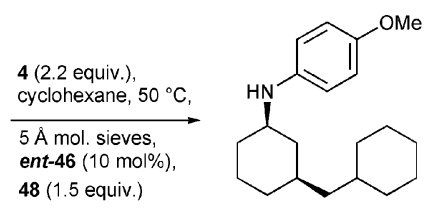

$8689 \%, 19: 1$ syn/anti, $96 \%$ ee
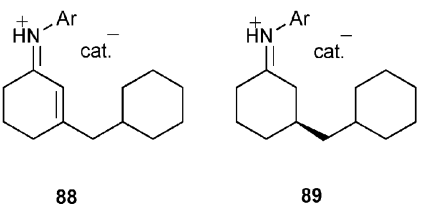

Scheme 18 Organocatalytic reductive cascade reaction.

the addition of methyl vinyl ketone (92) and a second charge of catalyst. Under these conditions, the Wieland-Miescher ketone analogue 93 could be prepared in moderate yield and $71 \%$ ee, along with the corresponding hydrated product 94 and pre-annulation substrate 95.

The authors postulated that the cascade involves an initial Knoevenagel condensation reaction between the acidic diketone and the aldehyde to form the electrophilic enone 96, which is then reduced by the Hantzsch ester (it was not suggested that this reaction is catalysed by the amine) to afford the $\alpha$-substituted product $\mathbf{9 7}$, which subsequently behaves as a Michael donor in a proline-catalysed reaction with 92 (to form 95) followed by cyclisation to give the bicyclic product (Scheme 19). ${ }^{71}$

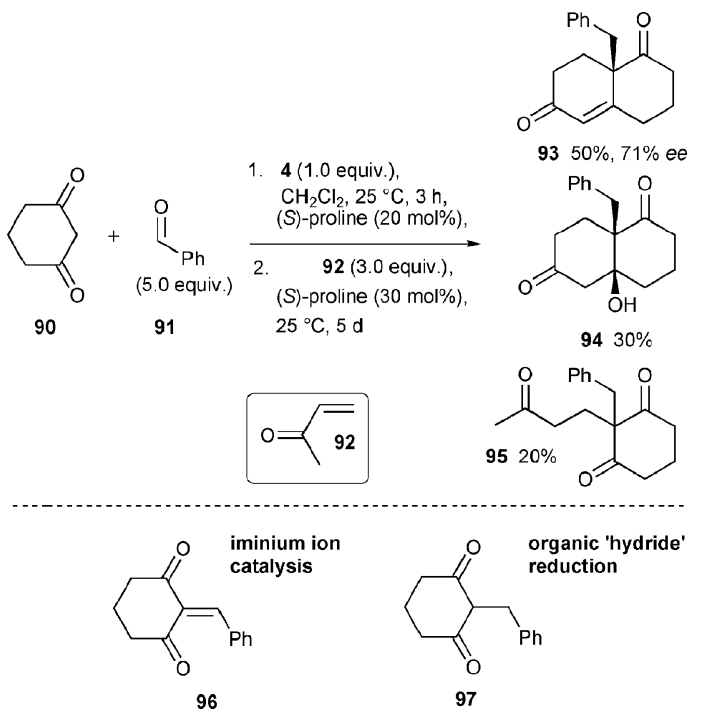

Scheme 19 Four component organocatalytic cascade reaction.

\section{(Thio)urea mediates catalysis of asymmetric organocatalytic reductions}

As mentioned earlier in the section describing enantioselective imine reduction, the last decade has witnessed the advent of a new class of (thio)urea-based hydrogen-bond donating catalyst pioneered by Curran and Kuo, ${ }^{72}$ Jacobsen and Sigman ${ }^{42}$ and Schreiner and Wittkopp ${ }^{73}$ for the activation of electrophiles incorporating $\mathrm{sp}^{2}$-hybridised heteroatoms that undergo an increase in basicity in the transition state of a given addition reaction..$^{6 a, g, h, k}$ Menche et al. reported that thiourea could catalyse the reductive amination of ketones $^{43 a}$ and aldehydes, ${ }^{43 b, 43 c}$ although Schreiner and Zhang ${ }^{43 d}$ have questioned some of these protocols (in particular the role played by activated/unactivated molecular sieves), this group also found that a more active 3,3',5,5'-tetratrifluoromethyl thiocarbanilide catalyst (98) at $10 \mathrm{~mol} \%$ levels was superior to thiourea as a promoter of ald- and ketoimine reductions by $\mathbf{4}$ in the absence of molecular sieves (Fig. 4). ${ }^{43 d}$ To date, no (thio)urea catalysed enantioselective variants of these reductive amination processes have appeared.<smiles>FC(F)(F)c1cc(NC(=S)Nc2cc(C(F)(F)F)cc(C(F)(F)F)c2)cc(C(F)(F)F)c1</smiles>

Fig. 4 3,3',5,5'-Tetratrifluoromethyl thiocarbanilide.

Inspired by the elegance and highly efficient enzymatic manipulation of the NAD $(\mathrm{P})+/ \mathrm{NAD}(\mathrm{P}) \mathrm{H}$ redox couple in living cells that allows constant 'regeneration' of the stoichiometric NAD(P)H reductant, our group have designed the first nicotinamide precatalyst 99 capable of both activating and reducing its substrate and that can be employed in catalytic amounts together with an inexpensive inorganic co-reductant in a two-phase system. ${ }^{74}$

Precatalyst 99 could efficiently reduce benzil (100) to benzoin (101) under the reactions conditions outlined in Scheme 20. Sodium dithionite continually reduces the oxidised pyridinium form of the dihydropyridine precatalyst (allowing it to be used at catalytic loadings ${ }^{75}$ and it was shown that both binary catalyst systems (separate thiourea and dihydropyridine catalysts) were inferior to 99 and that the background reaction in the absence of $\mathbf{9 9}$ gave only trace amounts of product. Unfortunately, while a similar enantiopure catalyst $\mathbf{1 0 2}$ is able to bring about asymmetric induction in this process, the product racemises under the reaction conditions (Scheme 20).

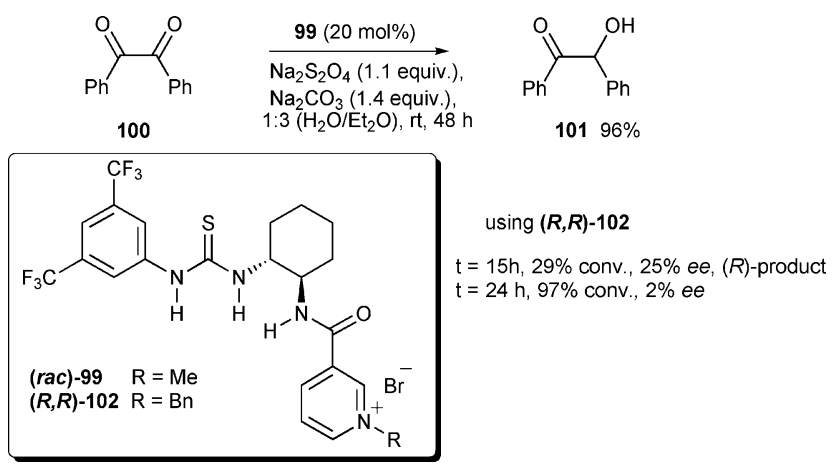

Scheme 20 Organocatalytic reduction of benzil using substoichiometric amounts of a dihydropyridine precatalyst.

List and co-workers ${ }^{76}$ have exploited the well established ability of suitably substituted (thio)urea derivatives to activate nitroalkenes towards attack by nucleophiles ${ }^{6, h, k}$ in the realisation of the first organocatalytic asymmetric nitroolefin reduction reaction (Scheme 21). For example, $(E)$ - $\alpha$-methyl- $\beta$-nitrosytrene (103) underwent smooth enantioselective reduction catalysed by 105 (an analogue of a catalyst developed by Jacobsen and Taylor 
for the promotion of asymmetric Pictet-Spengler reactions ${ }^{77}$ ) to afford 104 in excellent yield and 94\% ee. The ready availability of nitroolefin substrates and the high synthetic utility of the nitoalkane products makes this methodology a most promising development.

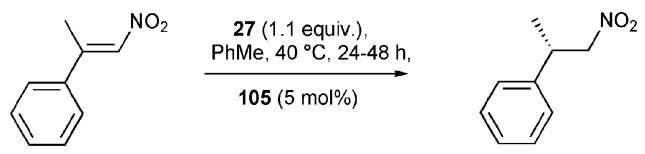

103

$10497 \%, 94 \%$ ee

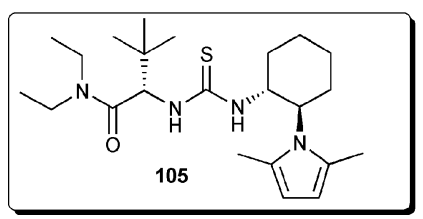

Scheme 21 Organocatalytic asymmetric nitroolefin reduction.

\section{Concluding remarks}

While the use of dihydropyridines to reduce organic substrates has been possible in the laboratory since the 1950 's, the recent general appreciation of the potential advantages associated with the design of chiral metal-free organocatalyst systems has breathed new life into this old, well-known reaction class. The first such metal-free asymmetric reduction was reported (and subsequently overlooked) in 1985, however, all major progress in this area has been made since 2004. These three years have been an exciting period characterised by success after success in the asymmetric dihydropyridine-mediated reduction of $\alpha, \beta$ unsaturated electrophiles and imines (including the reductive amination of ketones) in addition to the discovery of several highly useful-looking cascade processes. More encouraging still is the application of three diverse catalytic strategies (iminium ion-including counterion directed-catalysis, strong Brønsted acid catalysis and the use of hydrogen-bond donating catalysts), which augurs well for future expansion of the scope of these reactions. Frantic as the pace of progress has been, there is still scope for discovery with respect to both catalyst efficiency and substrate scope - in particular, the asymmetric reduction of simple ketones to sec-alcohols remains outside the domain of current catalyst technology. Regardless of future development in the field, these organocatalytic reduction reactions (which occur under mild conditions and do not require high pressures) already constitute highly useful complementary technologies to their well-established metal(ion)-mediated counterparts and they will doubtless find considerable synthetic application in the coming years.

\section{Notes and references}

1 (a) J. M. Brown, in Comprehensive Asymmetric Catalysis, ed. E. N. Jacobsen, A. Flats and H. Yamamoto, Springer, Berlin, 1999; (b) T. Ohkuma, M. Kitamura and R. Noyori, in Catalytic Asymmetric Synthesis, ed.I. Ojima, Wiley-VCH,New York, 2nd edn, 2000; (c) H. Brunner, W. Zettlmeier, Handbook of Enantioselective Catalysis, VCH,Weinheim, 1993; (d) H.-U. Blaser, C. Malan, B. Pugin, F. Spindler, H. Steiner and M. Studer, Adv. Synth. Catal., 2003, 345, 103; (e) Asymmetric Catalysis on Industrial Scale, ed. H.-U. Blaser and E. Schmidt, Wiley-VCH,Weinheim, 2004; $(f)$ G. Zassinovich, G.
Mestroni and S. Gladiali, Chem. Rev., 1992, 92, 1051; $(g)$ R. Noyori and S. Hashiguchi, Acc. Chem. Res., 1997, 30, 97; (h) T. Ikariya, K. Murata and R. Noyori, Org. Biomol. Chem., 2006, 4, 393; (i) S. Gladali and E. Alberico, Chem. Soc. Rev., 2006, 35, 226.

2 (a) W. S. Knowles and M. J. Sabacky, Chem. Commun. (London), 1968, 1445; (b) W. S. Knowles, Acc. Chem. Res., 1983, 16, 106; (c) W. S. Knowles, Angew. Chem., Int. Ed., 2002, 41, 1998.

3 (a) A. Miyashita, A. Yasuda, H. Takaya, K. Toriumi, T. Ito, T. Souchi and R. Noyori, J. Am. Chem. Soc., 1980, 102, 7932; (b) R. Noyori, Angew. Chem., Int. Ed., 2002, 41, 2008.

4 Examples: (a) A. Lightfoot, P. Schnider and A. Pfaltz, Angew. Chem., Int. Ed., 1998, 37, 2897; (b) K. Källstrom, C. Hedberg, P. Brandt, A. Bayer and P. G. Andersson, J. Am. Chem. Soc., 2004, 126, 14308; (c) S. Bell, B. Wüstenberg, S. Kaiser, F. Menges, T. Netscher and A. Pfaltz, Science, 2006, 311, 642.

5 While organocatalysis has developed at a rapid pace only recently, its origins stretch back to the beginning of the previous century. For selected early examples of asymmetric organocatalysis see: $(a) \mathrm{G}$. Bredig and K. Fajans, Ber. Dtsch. Chem. Ges., 1908, 41, 752; (b) G. Bredig and P. S. Fiske, Biochem. Z., 1912, 46, 7; (c) R. Wegler, Ann., 1932, 498, 62; (d) V. Prelog and H. Wilhelm, Helv. Chim. Acta, 1954, 37, 1634; (e) H. Pracejus, Justus Liebigs Ann. Chem., 1960, 634, 9; (f) D. Borrmann and R. Wegler, Chem. Ber., 1967, 100, 1575; $(g)$ H. Wynberg and R. Helder, Tetrahedron Lett., 1975, 16, 4057.

6 (a) Recent reviews: G. Lelais, D. W. C. MacMillan, in Frontiers in Asymmetric Catalysis, ed. K. Mikami and M. Lautens, Wiley, Hoboken, 2007; (b) D. Almaşi, D. A. Alonso and C. Nájera, Tetrahedron: Asymmetry, 2007, 18, 299; (c) R. M. de Figueiredo and M. Christmann, Eur. J. Org. Chem., 2007, 2575; (d) S. B. Tsogoeva, Eur. J. Org. Chem., 2007, 1701; (e) M. J. Gaunt, C. C. C. Johansson, A. McNally and N. T. Vo, Drug Discovery Today, 2006, 12, 8; ( $f$ ) B. List, Chem. Commun., 2006, 819; (g) M. S. Taylor and E. N. Jacobsen, Angew. Chem., Int. Ed., 2006, 45, 1520; (h) S. J. Connon, Chem.-Eur. J., 2006, 12, 5418; (i) T. Akiyama, J. Itoh and K. Fuchibe, Adv. Synth. Catal., 2006, 348, 999; (j) S. J. Connon, Lett. Org. Chem., 2006, 3, 333; (k) Y. Takemoto, Org. Biomol. Chem., 2005, 3, 4299; (l) S. Jayasree and B. List, Org. Biomol. Chem., 2005, 3, 719; (m) P. M. Pihko, Angew. Chem., Int. Ed., 2004, 43, 2062; (n) A. Berkessel, H. Gröger, Asymmetric Organocatalysis, Wiley, Weinheim, 2005; (o) P. I. Dalko and L. Moisan, Angew. Chem., Int. Ed., 2004, 43, 5138; (p) K. N. Houk and B. List, Acc. Chem. Res., 2004, 37(8), special issue on organocatalysis; $(q)$ P. M. Pihko, Angew. Chem., Int. Ed., 2004, 43, 2062; (r) P. R. Schreiner, Chem. Soc. Rev., 2003, 32, 289.

7 H. Adolfsson, Angew. Chem., Int. Ed., 2005, 44, 3340.

8 J. M. Berg, J. L. Tymoczko, L. Stryer, Biochemistry, Freeman, New York, 5th edn, 2002.

9 D. Mauzerall and F. H. Westheimer, J. Am. Chem. Soc., 1955, 77, 2261.

10 Karrer and co-workers had earlier shown that 1,4-dihydropyridines could reduce methylene blue, however, proof of direct hydrogen transfer could not be obtained (via deuterium labelling experiments) due to the likelihood of fast exchange of the transferred H/D in the product with the solvent. P. Karrer, B. H. Riniger, J. Buchi, H. Fritzsche and U. Solmssen, Helv. Chim. Acta, 1937, 20, 55.

11 A. Hantzsch, Justus Liebigs Ann. Chem., 1882, 215, 1.

12 For a later study demonstrating the reduction of other keto acids see: R. H. Arles and F. H. Westheimer, J. Am. Chem. Soc., 1958, 80, 5450.

13 R. H. Arles, R. F. Hutton and F. H. Westheimer, J. Am. Chem. Soc., $1957,79,712$.

14 For examples see: (a) J. Hajdu and D. S. Sigman, J. Am. Chem. Soc, 1976, 98, 6060; (b) D. Creighton, J. Hajdu, G. Mooser and D. S. Sigman, J. Am. Chem. Soc., 1973, 95, 6855; (c) S. Shinkai, T. Tsuno and O. Manabe, Chem. Lett., 1981, 1203; (d) J. Steffens and D. Chipman, J. Am. Chem. Soc., 1971, 93, 6694.

15 M. F. Powell and T. C. Bruice, J. Am. Chem. Soc., 1983, 105, 7139.

16 For overviews see: (a) A. Ohno, J. Phys. Org. Chem., 1995, 8, 567; (b) J. Gębicki, A. Marcinek and J. Zielonka, Acc. Chem. Res., 2004, 37, 379; (c) Y. Ishikawa, N. Yamazaki, M. Okamura and Y. Kawai, J. Am. Chem. Soc., 1998, 120, 1186.

17 For examples of electron transfer mechanisms with potent oxidants see: (a) B. Carlson and L. Miller, J. Am. Chem. Soc., 1983, 105, 7453; (b) B. Carlson, L. Miller, P. Neta and J. Grodkowski, J. Am. Chem. Soc., 1984, 106, 7233; (c) T. Okamoto, T. Ohno and S. Oka, J. Chem. Soc., Chem. Commun., 1977, 784. 
18 Examples: (a) J. W. Bunting, V. S. F. Chew and G. Chu, J. Org. Chem., 1982, 47, 2308; (b) R. Srinivasan, R. T. Medary, H. F. Fisher, D. J. Norris and R. Stewart, J. Am. Chem. Soc., 1982, 104, 807; (c) M. F. Powell and T. C. Bruice, J. Am. Chem. Soc., 1983, 105, 1014.

19 For reviews of dihydropyridine chemistry see: (a) R. Lavilla, J. Chem. Soc., Perkin Trans. 1, 2000, 1141; (b) M. Lounasmaa, A. Tolvanen, in Comprehensive Heterocyclic Chemistry II, ed. A. R. Katritzky, C. W. Rees and E. F. V. Scriven, Pergamon, Oxford, 1996, vol. 5, p. 135; (c) U. Eisner and J. Kuthan, Chem. Rev., 1972, 72, 1; (d) D. M. Stout and A. I. Meyers, Chem. Rev., 1982, 82, 223; (e) A. Sausins and G. Duburs, Khim. Geterotsikl. Soedin., 1993, 579; (f) A. Sausins and G. Duburs, Heterocycles, 1988, 27, 291; ( $g$ ) J. P. Kutney, Heterocycles, 1977, 7, 593; (h) D. L. Comins and S. O'Connor, Adv. Heterocycl. Chem., 1988, 44, 199; (i) R. Kumar and R. Chandra, Adv. Heterocycl. Chem., 2001, 78, 269.

20 For selected examples see: (a) X.-Q. Zhu, H.-Y. Wang, J.-S. Wang and Y.-C. Liu, J. Org. Chem., 2001, 66, 344; (b) S. Yasui, M. Fujii and A. Ohno, Bull. Chem. Soc. Jpn., 1987, 60, 4019; (c) Y. Inoue, S. Imaizumi, H. Itoh, T. Shinya, H. Hashimoto and S. Miyano, Bull. Chem. Soc. Jpn., 1988, 61, 3020; (d) K. Nakamura, M. Fujii, S. Oka and A. Ohno, Chem. Lett., 1987, 60, 963; (e) M. Fujii, Bull. Chem. Soc. Jpn., 1988, 61, 4029; (f) U. K. Pandit, F. R. M. Cabré, R. A. Gase and M. J. de Nie-Sarink, J. Chem. Soc., Chem. Commun., 1974, 627; (g) M. Fujii, T. Aida, M. Yoshihara and A. Ohno, Bull. Chem. Soc. Jpn., 1990, 63, 1255; (h) U. K. Pandit, J. B. Steevens and F. R. Mas Cabré, Bioorg. Chem., 1973, 2, 293; (i) S. Torchy, G. Cordonnier, D. Barbry and J. J. Vanden Eynde, Molecules, 2002, 7, 528; (j) S. Yasui, M. Fujii, K. Nakamura and A. Ohno, Bull. Chem. Soc. Jpn., 1988, 61, 3020; (k) X.-Q. Zhu and Y.-C. Liu, J. Org. Chem., 1998, 63, 2786; (l) X.-Q. Zhu, Y.-C. Liu and J.-P. Cheng, J. Org. Chem., 1999, 63, 8980; (m) C. A. Coleman, J. G. Rose and C. J. Murray, J. Am. Chem. Soc., 1992, 114, 9755; (n) H.-J. Xu, G. Deng and Q. Yu, J. Chem. Soc., Chem. Commun., 1987, 916; (o) S. J. Garden, C. R. W. Guimarães, B. Corréa, C. A. F. Oliveira, A. C. Pinto and R. B. Alencastro, J. Org. Chem., 2003, 68, 8815; (p) Z. Lui, B. Han, Q. Lui, W. Zhang, L. Yang, Z. L. Lui and W. Wu, Synlett, 2005, 1579.

21 For selected examples see: (a) M. Fujii, K. Kawaguchi, K. Nakamura and A. Ohno, Chem. Lett., 1992, 1493; (b) T. Itoh, K. Nagata, A. Kurihara, M. Miyazaki and A. Ohsawa, Tetrahedron Lett., 2002, 43, 3105; (c) T. Itoh, K. Nagata, M. Miyazaki, H. Ishikawa, A. Kurihara and A. Ohsawa, Tetrahedron, 2004, 60, 6649; (d) S. Singh and U. Kaur, Indian J. Chem., Sect. B: Org. Chem. Incl. Med. Chem., 1987, 26B, 199; (e) S. Singh, I. Singh, R. K. Sahota and S. Nagrath, J. Chem. Soc., Perkin Trans. 1, 1986, 2091; (f) H. P. Merjer, J. C. G. Van Niel and U. K. Pandit, Tetrahedron, 1984, 40, 5185.

22 U. K. Pandit, R. A. Gase, F. R. Mas Cabré and M. J. de Nie-Sarink, J. Chem. Soc., Chem. Commun., 1975, 211.

23 For examples see: (a) S. Shinkai and T. C. Bruice, Biochemistry, 1973, 12, 1750; (b) U. K. Pandit and F. R. Mas Cabré, J. Chem. Soc. D, 1971, 552; (c) S. Fukuzumi, M. Ishikama and T. Tanaka, Tetrahedron, 1984, 42, 1021.

24 For examples see: (a) K. Nishiyama, N. Baba, J. Oda and Y. Inouye, J. Chem. Soc., Chem. Commun., 1976, 101; (b) S. Fukuzumi, S. Mochizuki and T. Tanaka, J. Am. Chem. Soc., 1989, 111, 1497; (c) D. D. Tanner, H. K. Singh, A. Kharrat and A. R. Stein, J. Org. Chem., 1987, 52, 2141; (d) D. D. Tanner and A. R. Stein, J. Org. Chem., 1988, 53, 1642.

25 For example — xanthylium ions: (a) J.-P. Cheng and Y. Li, J. Phys. Org. Chem., 1997, 10, 577, aryl alcohols, arylethylenes and trityl ethers; (b) S. Singh, S. Gill, V. K. Sharma and S. Nagrath, J. Chem. Soc., Perkin Trans. 1, 1986, 1273, sulfonium ions; (c) T. J. van Bergen and R. M. Kellogg, J. Am. Chem. Soc., 1976, 98, 1962.

26 N. Kanomata and T. Nakata, Angew. Chem., Int. Ed. Engl., 1997, 36, 1207.

27 N. Kanomata and T. Nakata, J. Am. Chem. Soc., 2000, 122, 4563.

28 For further examples see: (a) Y. Ohnishi, M. Kagami and A. Ohno, J. Am. Chem. Soc., 1975, 97, 4766; (b) T. Endo, Y. Hayashi and M. Okawara, Chem. Lett., 1977, 6, 391; (c) J. G. de Vries and R. M. Kellogg, J. Am. Chem. Soc., 1979, 101, 2759; (d) A. Ohno, M. Ikeguchi, T. Kimura and S. Oka, J. Am. Chem. Soc., 1979, 101, 7036; (e) P. Jouin, C. B. Troostwijk and R. M. Kellogg, J. Am. Chem. Soc., 1981, 103, 2091; (f) A. Ohno, J. Nakai, K. Nakamura, T. Goto and S. Oka, Bull. Chem. Soc. Jpn., 1981, 54, 3482; (g) M. Seki, N. Baba, J. Oda and Y. Inouye, J. Am. Chem. Soc., 1981, 103, 4613; (h) M. Seki, N. Baba, J. Oda and Y. Inouye, J. Org. Chem., 1983, 48, 1370; (i) A. G. Talma, P. Jouin, J. G. de Vries, C. B. Troostwijk, G. H. Werumeus Buning, J. K. Waninge, J. Visscher and R. M. Kellogg, J. Am. Chem. Soc., 1985, 107, 3981; (j) S. Yasui and A. Ohno, Bioorg. Chem., 1986, 14, 70; $(k)$ A. I. Meyers and T. Oppenlaender, J. Am. Chem. Soc., 1986, 108, 1989; (l) T. Imanishi, Y. Hamano, H. Yoshikawa and C. Iwata, J. Chem. Soc., Chem. Commun., 1988, 473; (m) V. A. Burgess, S. G. Savies and R. T. Skerlj, J. Chem. Soc., Chem. Commun., 1990, 1759; (n) V. A. Burgess, S. G. Savies, R. T. Skerlj and M. Whittaker, Tetrahedron: Asymmetry, 1992, 3, 871; (o) Y. Combret, J.-J. Torché, N. Plé, J. Duflos, G. Dupas, J. Bourguignon and G. Quéguiner, Tetrahedron, 1991, 47, 9369; ( $p$ ) Y. Combret, J. Duflos, G. Dupas, J. Bourguignon and G. Quéguiner, Tetrahedron, 1993, 49, 5237; $(q)$ A. Ohno, A. Tsutsumi, Y. Kawai, N. Yamazaki, Y. Mikata and Y. Okamura, J. Am. Chem. Soc., 1994, 116, 8133; (r) J. L. Vasse, P. Charpentier, V. Lavacher, G. Dupas, G. Quéguiner and J. Bourguignon, Synlett, 1998, 1144; (s) U. Gran, O. Wennerström and G. Westman, Tetrahedron: Asymmetry, 2000, 11, 3027; $(t)$ Y. Mikata, K. Mizukami, K. Hayashi, S. Matsumoto, S. Yano, N. Yamazaki and A. Ohno, J. Org. Chem., 2001, 66, 1590; (u) R. Saito, S. Naruse, K. Takano, K. Fukuda, A. Katoh and Y. Inoue, Org. Lett., 2006, 8, 2067.

29 For a recent example of a chiral metal-based catalyst promoting enantioselective reductions of $\alpha$-keto esters using stoichiometric loadings of a Hanztsch dihydropyridine see: J. W. Yang and B. List, Org. Lett., 2006, 8, 5653.

30 K. A. Ahrendt, C. J. Borths and D. W. C. MacMillan, J. Am. Chem. Soc., 2000, 122, 4243.

31 For a recent review of iminium ion catalysis see: G. Delais and D. W. C. MacMillan, Aldrichimica Acta, 2006, 39, 79 .

32 For an example of the use of such a system in natural product synthesis see: R. M. de Figueiredo, R. Berner, J. Julis, T. Liu, D. Türp and M. Christmann, J. Org. Chem., 2007, 72, 640.

33 J. W. Wang, M. T. Hechavarria Fonseca and B. List, Angew. Chem., Int. Ed., 2004, 43, 6660.

34 J. W. Wang, M. T. Hechavarria Fonseca, N. Vignola and B. List, Angew. Chem., Int. Ed., 2005, 44, 108.

35 S. G. Ouellet, J. B. Tuttle and D. W. C. MacMillan, J. Am. Chem. Soc., 2005, 127, 32.

36 A. B. Northrup and D. W. C. MacMillan, J. Am. Chem. Soc., 2002, 124, 7894

37 J. B. Tuttle, S. G. Oulette and D. W. C. MacMillan, J. Am. Chem. Soc., 2006, 128, 12662.

38 S. Mayer and B. List, Angew. Chem., Int. Ed., 2006, 45, 4193.

39 N. J. A. Martin and B. List, J. Am. Chem. Soc., 2006, 128, 13368.

40 For reviews concerning general acid-base catalysis see: (a) W. P. Jencks, Chem. Rev., 1972, 72, 705; (b) W. P. Jencks, Acc. Chem. Res., 1976, 9, 425; (c) W. P. Jencks, Acc. Chem. Res., 1980, 13, 161.

41 For a review concerning recent developments in both metal-free and metal-assisted Brønsted acid catalysts see: H. Yamamoto and $\mathrm{K}$. Futatsugi, Angew. Chem., Int. Ed., 2005, 44, 1924.

42 For the seminal work see: M. S. Sigman and E. N. Jacobsen, J. Am. Chem. Soc., 1998, 120, 4901.

43 For reports concerning the reduction of imines/reductive amination of aldehydes/ketones using achiral thiourea catalysts see: (a) D. Menche, J. Hassfeld, G. Menche, A. Ritter and S. Rudolph, Org. Lett., 2006, 8, 741; (b) D. Menche and F. Arikan, Synlett, 2006, 841; (c) D. Menche, S. Böhm, J. Li, S. Rudolph and W. Zander, Tetrahedron Lett., 2007, 48, 365; (d) Z. Zhang and P. R. Schreiner, Synlett, 2007, 1455.

44 S. Singh and U. K. Batra, Ind. J. Chem., 1989, 28B, 1.

45 The authors use optical rotation data to determine levels of enantiomeric excess and cite previous work by Kagan et al., curiously the absolute configuration of $\mathbf{3 6}$ is not given by Singh even though it was determined by Kagan. We have assumed that Singh used the same conditions as Kagan in assigning the absolute configuration of 36: H. B. Kagan, N. Langois and T. P. Dang, J. Organomet. Chem., 1975, 90, 353 .

46 T. Akiyama, J. Itoh, K. Yokota and K. Fuchibe, Angew. Chem., Int. Ed., 2004, 43, 1566.

47 D. Uraguchi and M. Terada, J. Am. Chem. Soc., 2004, 126, 5356.

48 For a short monograph concerning the use of chiral phosphoric acids as catalysts for enantioselective addition reactions to imines see: S. J. Connon, Angew. Chem., Int. Ed., 2006, 45, 3909.

49 The $\mathrm{p} K_{\mathrm{a}}$ of diethyl phosphate is 1.39: L. D. Quin, A Guide to Organophosphorus Chemistry, John Wiley \& Sons, New York, 2000, ch. 5.

50 For a review detailing the use of phosphoric acid catalysts in other asymmetric transformations see ref. $6 i$. 
51 M. Rueping, E. Sugiono, C. Azap, T. Theissmann and M. Bolte, Org. Lett., 2005, 7, 3781.

52 At the same time the authors reported the non-asymmetric version of the reaction using an achiral phosphoric acid: M. Rueping, C. Azap, E. Sugiono, T. Theissmann and M. Bolte, Synlett, 2005, 2367.

53 S. Hoffman, A. M. Seayad and B. List, Angew. Chem., Int. Ed., 2005, 44, 7424 .

54 R. I. Storer, D. E. Carrera, Y. Ni and D. W. C. MacMillan, J. Am Chem. Soc., 2006, 128, 84.

55 S. Hoffmann, M. Nicoletti and B. List, J. Am. Chem. Soc., 2006, 128, 13074.

56 G. Li, Y. Liang and J. C. Antilla, J. Am. Chem. Soc., 2007, 129, 5830.

57 For a previous example where VAPOL-derived phosphoric acids proved superior to BINOL-based materials see: G. B. Rowland, H. Zhang, E. B. Rowland, S. Chennamadhavuni, Y. Wang and J. C. Antilla, J. Am. Chem. Soc., 2005, 127, 15696.

58 Review: V. I. Tararov and A. Börner, Synlett, 2005, 203.

59 M. Rueping, A. P. Antonchick and T. Thiessmann, Angew. Chem., Int. Ed., 2006, 45, 3683.

$60 \mathrm{~A}$ short time afterwards the same group reported a non-chiral variant of this process: M. Rueping, T. Thiessmann and A. P. Antonchick, Synlett, 2006, 1071.

61 M. Rueping and A. P. Antonchick, Angew. Chem., Int. Ed., 2007, 46, 4562.

62 M. Rueping, A. P. Antonchick and T. Thiessmann, Angew. Chem., Int. Ed., 2007, 45, 6751.

63 For interesting reports detailing non-catalysed reductions of exocyclic olefins in heterocyclic systems see: (a) S. J. Garden, C. R. Werneck Guimarães, M. B. Corréa, C. A. Fernandes de Oliveira, A. da Cunha Pinto and R. B. de Alencastro, J. Org. Chem., 2003, 68, 8815; (b) Z. Liu, B. Han, Q. Liu, W. Zhang, L. Yang, Z.-L. Liu and W. Yu, Synlett, 2005,1579 .
64 For recent reviews see: (a) D. Enders, C. Grondal and M. R. M. Hüttl, Angew. Chem., Int. Ed., 2007, 46, 1570; (b) M. Rueping, Nachr. Chem., 2007, 55, 35; (c) G. Guillena, D. J. Ramon and M. Yus, Tetrahedron: Asymmetry, 2007, 18, 693.

65 Y. Huang, A. M. Walji, C. H. Larsen and D. W. C. MacMillan, J. Am. Chem. Soc., 2006, 127, 15051.

66 The authors point out that combining asymmetric processes results in a mathematical requirement for an improvement in enantioselectivity. For example, if two catalytic cycles are combined, both of which give products with $86 \%$ ee, the cascade will give a $7: 1$ mixture of diastereomers and the major diastereomer will be formed in $99 \%$ ee.

67 J. W. Yang, M. T. Hechavarria Fonseca and B. List, J. Am. Chem. Soc., 2005, 127, 15036.

68 G.-L. Zhao and A. Córdova, Tetrahedron Lett., 2006, 47, 7417.

69 J. Zhou and B. List, J. Am. Chem. Soc., 2007, 129, 7498.

70 D. B. Ramachary and M. Kishor, J. Org. Chem., 2007, 72, 5056.

71 For a second report detailing a $(S)$-proline catalysed domino process involving a reduction reaction that does not generate enantioenriched products see: D. B. Ramachary, M. Kishor and G. B. Reddy, Org. Biomol. Chem., 2006, 4, 1641.

72 (a) D. P. Curran and L. H. Kuo, J. Org. Chem., 1994, 59, 3259; (b) D. P. Curran and L. H. Kuo, Tetrahedron Lett., 1995, 36, 6647.

73 (a) P. R. Schreiner and A. Wittkopp, Org. Lett., 2002, 4, 217; (b) P. R. Schreiner and A. Wittkopp, Chem.-Eur. J., 2003, 9, 407.

74 B. Procuranti and S. J. Connon, Chem. Commun., 2007, 1421.

75 For a similar strategy in a photoinduced dihydropyridine-mediated reduction of chalcone oxides not under the influence of catalysis see: H.-J. Xu, Y.-C. Liu, Y. Fu and Y.-D. Wu, Org. Lett., 2006, 8, 3449.

76 N. J. A. Martin, L. Ozores and B. List, J. Am. Chem. Soc., 2007, 129, 8976.

77 M. S. Taylor and E. N. Jacobsen, J. Am. Chem. Soc., 2004, 126, 10558. 